\title{
CYP2D6 PHENOTYPES AMONG JAVANESE AND SUNDANESE SUBJECTS IN INDONESIA
}

\author{
PRI ISWATI UTAMI ${ }^{1,2 *}$, SUGIYANTO SUGIYANTO ${ }^{3}$, SUDIBYO MARTONO ${ }^{4}$, LUKMAN HAKIM ${ }^{3}$
}

${ }^{1}$ Department of Pharmaceutical Chemistry, Faculty of Pharmacy, Universitas Muhammadiyah Purwokerto, Jl. Raya Dukuhwaluh, Kembaran, Purwokerto, Central Java, Indonesia. ${ }^{2}$ Post Graduate Program, Faculty of Pharmacy, Gadjah Mada University, Sekip Utara, Yogyakarta, Indonesia. ${ }^{3}$ Department of Pharmacology and Clinical Pharmacy, Faculty of Pharmacy, Gadjah Mada University, Sekip Utara, Yogyakarta, Indonesia. ${ }^{4}$ Department of Pharmaceutical Chemistry, Faculty of Pharmacy, Gadjah Mada University, Sekip Utara, Yogyakarta, Indonesia. Email: priiswatiutami@ump.ac.id

Received: 15 March 2019, Received and Accepted: 20 July 2019

ABSTRACT

Objective: The objective of this study was to determine CYP2D6 phenotype in a Javanese and Sundanese healthy subject in Indonesia.

Methods: Ninety unrelated healthy Indonesian subjects from Java and Sunda were studied. Metoprolol was used as phenotyping substrate. A 100 mg oral tablet of metoprolol was administered to all the subjects. Urinary metoprolol and $\alpha$-hydroxymetoprolol were determined to calculate metoprolol metabolic ratio (MR). Determination of metoprolol and $\alpha$-hydroxymetoprolol was carried out by high performance liquid chromatography method.

Results: Metoprolol MR varied widely (from 0.08 to 72.75$)$. One subject (1.11\%) in the study was classified as poor metabolizer (PM), one subject $(1.11 \%)$ as ultrarapid metabolizer, and the remaining 88 subjects $(97.78 \%)$ were classified as extensive metabolizers.

Conclusion: The frequencies of PM for the CYP2D6 phenotype (1.11\%) in the Javanese and Sundanese population are in concordance with most results of oxidation metabolizers in other Asian populations.

Keywords: CYP2D6, Javanese and Sundanese, Indonesia, Metoprolol, Phenotype.

(C) 2019 The Authors. Published by Innovare Academic Sciences Pvt Ltd. This is an open access article under the CC BY license (http://creativecommons. org/licenses/by/4. 0/) DOI: http://dx.doi.org/10.22159/ijap.2019.v11s5.T0038

\section{INTRODUCTION}

CYP2D6, a minor form of CYP isoforms is only about $2 \%$ of the total CYP but has an important contribution in the metabolism of approximately 20$25 \%$ of drugs used in the clinic, including $\beta$-blockers and antiarrhythmic agents. This enzyme activity catalyzes the Phase I reaction of drug metabolism which may determine the effects of the drug. Variability in drug metabolism between individuals often happens; the consequence is that at therapeutic doses may vary among individuals which, in turn, may result in adverse drug reaction or no therapeutic response. CYP2D6 along with CYP2C9 and CYP2C19 has a high polymorphism approximately 40\% of Phase I hepatic metabolism. Phenotyping study of CYP2D6 enzyme activity can be measured in vivo after oral administration of a single dose of the drug which is a substrate of the enzyme. The urinary metabolic ratio (MR) between the parent drug and its metabolites was determined as an indicator of polymorphism [1-3]

Probes commonly used to measure the in vivo activity of CYP2D6 are debrisoquine, metoprolol, and dextromethorphan, but unfortunately debrisoquine not available for use in humans in many countries including Indonesia so that metoprolol can be used as a probe because it is not affected by changes of $\mathrm{pH}$ of urine [4].

Metoprolol is adrenoceptor antagonist ( $\beta$-blockers) which has been used extensively for more than 25 years to treat cardiovascular disorders such as hypertension, arrhythmia, and heart failure [1,5]. Metoprolol has extensively experienced the first-pass metabolism so that the biological availability of only about $50 \%$ [6]. Specifically, CYP2D6 catalyzes the $\alpha$-hydroxylation of metoprolol which produces metabolites $\alpha$-hydroxymetoprolol [7]. A Pharmacokinetic study in the South Indian population showed variability in the plasma concentration of the drug after administration of metoprolol at standard doses [8].

In this study, the oxidation capacity of metoprolol in Indonesian healthy subjects is determined by determining the urinary MR of metoprolol and $\alpha$-hydroxymetoprolol after single-dose administration of $100 \mathrm{mg}$ metoprolol tartrate orally. Furthermore, the phenotype is determined whether including ultrarapid metabolizer (UM), extensive metabolizer (EM), intermediate metabolizer (IM), or poor metabolizer (PM).

\section{MATERIALS AND METHODS}

The study protocol was approved by the Health Research Ethics Committee of the Faculty of Medicine, Gadjah Mada University, Indonesia.

\section{Materials}

Metoprolol tartrate reference standard and caffeine used as internal standard were purchased from Sigma-Aldrich, St. Louis, MO, USA. $\alpha$-Hidroksimetoprolol reference standard was purchased from Toronto Research Chemical. Acetonitrile and methanol (high-performance liquid chromatographic [HPLC] grade), sodium hydroxide, and orthophosphoric acid (analytical grade) were obtained from Merck and Co., Germany; $0.45 \mu \mathrm{m}$ membrane filter, aqua bidestilata, and deionized water from PT. Otsuka, Japan, were used.

\section{Methods}

Subject

The study involved 90 Indonesian healthy subjects (19.58 \pm 1.47 years). All the participants were given the explanation and signed written informed consent to participate in the research. Volunteers are both man and woman from the Javanese and Sundanese. Volunteers in good health condition based on a physical examination, clinical laboratory tests which include liver and kidney function, examination of the heart electrocardiogram, and no history of serious illness, do not have a history of liver and kidney disorders, weight within the normal range. Exclusion criteria: Smokers: Women who use oral contraceptives, pregnant and/or lactating women, obesity, a history of gastrointestinal disorders, she has a history of dependence on alcohol or drug abuse, are taking metoprolol, 
contraindications or hypersensitivity to metoprolol sinus bradycardia, cardiogenic shock and heart failure, a history of bronchospasm or asthma, heart rate $<45$ beats/min, heart block Grade 2 and 3, systolic blood pressure $<100 \mathrm{mmHg}$, or heart failure moderate to heavily.

\section{Phenotype Study of CYP2D6 using metoprolol}

The subjects were not allowed to take any medication or consume alcoholic beverages and drinks/foods containing caffeine for 1 week before administration. The subjects received a single dose of metoprolol tartrate tablets $(100 \mathrm{mg}$ ) orally with $200 \mathrm{~mL}$ of water after overnight fasting before administration of the drug. Urine was collected for $8 \mathrm{~h}$ from the time taking metoprolol tablets. Urine samples were stored at $-40^{\circ} \mathrm{C}$ before analysis.

Liquid-liquid extraction was performed using dichloromethane solvent after the addition of sodium hydroxide into the urine sample. The reversed-phase HPLC method [9] was slightly modified and used for the determination of $\alpha$-hydroxymetoprolol and metoprolol in urine samples. Separation was carried out in a Purospher ${ }^{\circledR}$ STAR RP18e LiChroCART ${ }^{\circledR}(250 \times 4.6 \mathrm{~mm}, 5 \mu \mathrm{m})$ column with a mobile phase consisting of a mixture of $25 \mathrm{mM} \mathrm{KH}_{2} \mathrm{PO}_{4}$ solution ( $\mathrm{pH}$ was adjusted into 3 with orthophosphoric acid)-acetonitrile-methanol (70:15:15, v/v) with a flow rate of $1 \mathrm{ml} / \mathrm{min}$ and injection volume of $20 \mu \mathrm{l}$. The Ultraviolet detector was set at $\lambda 234 \mathrm{~nm}$. Quantification of $\alpha$-hydroxymetoprolol and metoprolol was performed using internal standard caffeine.

Urinary metoprolol and $\alpha$-hydroxymetoprolol were determined to calculate metoprolol MR. Based on the MR (or LogMR) value, the phenotype of the test subjects was classified as a PM with MR $>12.6$ ( $\log M R>1.1)$, IM and EM with $0.1<\mathrm{MR}<12.6(-1.0<\log \mathrm{MR}<1.1)$, and UM with $M R<0.1(\log M R<-1.0)$.

\section{Data analysis}

CYP2D6 enzyme activity was determined by determining the ratio of the molar concentration of metoprolol/ $\alpha$-hydroxymetoprolol in the urine. The ratio of metoprolol and $\alpha$-hydroxymetoprolol in the urine (MR) was calculated by the following equation:

$\mathrm{MR}=($ metoprolol $) /(\alpha$-hydroxymetoprolol $)$

The phenotype was determined by the MR. Subjects with MR $>12.6$ were classified as PM, subjects with MR 0.1-12.6 were classified as IM and EM, and subjects with MR $<0.1$ were classified as UM [10].

Table 1: Characteristics of 90 subjects who participated in this study

\begin{tabular}{lll}
\hline $\begin{array}{l}\text { Subject } \\
\text { characteristics }\end{array}$ & $\begin{array}{l}\text { Number/ } \\
\text { Value }\end{array}$ & Percentage (\%) \\
\hline $\begin{array}{l}\text { Age (years) } \\
\text { Gender }\end{array}$ & $19.58 \pm 1.47$ & \\
$\quad$ Man & 34 & 37.78 \\
$\quad$ Female & 56 & 62.22 \\
Tribe & & \\
$\quad$ Javanese & 72 & 80 \\
$\quad$ Sundanese & 18 & 20 \\
Weight (kg) & & \\
$\quad$ Man & $57.97 \pm 7.64$ & \\
Female & $49.48 \pm 7.63$ & \\
Height (cm) & & \\
Man & $167.21 \pm 5.83$ & \\
Female & $156.18 \pm 5.50$ & \\
\hline
\end{tabular}

\section{RESULTS AND DISCUSSION}

Characteristics of the subjects who participated in this study can be shown in Table 1. In this study, factors that can change the absorption, distribution, metabolism, and excretion of the drug are controlled. These factors include age, pregnancy, ethnicity, pathological conditions, obesity, consumption of drugs or other compounds, and time of administration of the drug.

The MR value of the subjects had a very wide range (from 0.08 to 72.75). MR distribution patterns are displayed as a histogram in Fig. 1. As shown in the histogram, the distribution of MR showed the presence of three different phenotypes. A clear-cut point between 9.84 and 72.75 MR value was 12.6 (anti-mode). To determine metabolizer status to metoprolol, 12.6 is used as anti-mode [11]. Anti-mode for debrisoquine and metoprolol has proved equally on studies for the Turkish population and the other Caucasian population [12].

Based on the phenotyping study, there are differences in the hydroxylation capacity of metoprolol in the Javanese and Sundanese healthy subjects groups (Table 2). Metoprolol MR varied widely. The MR data are in the range from 0.1 to 74.9 with a median of 1.3. The LogMR value range is $-1.1-1.9$ with a median of 0.1 . One subject from Sundanese women $(1.11 \%)$ in the study was classified as PM, one subject from Javanese women $(1.11 \%)$ as $\mathrm{UM}$, and the remaining 88 subjects $(97.78 \%)$ were classified as EM.

There is no evidence of significantly different between the subjects for the LogMR value between Javanese and Sundanese subjects based on the Mann-Whitney U-test ( $p>0.05)$. LogMR and MR values mostly are above the median value either for women test subjects or men. This illustrates that the metoprolol metabolism capacity of the women and men subject, in general, is similar.

The results of this study are different from the previous studies. Studies with CYP2D6 substrate, especially dextromethorphan, showed that in EM individuals, there was a shift in the value of dextromethorphan/ dextrorphan MR for female subjects compared to MR values in male subjects. The CYP2D6 activity in male subjects was higher than in female subjects [13]. The results of studies on other CYP2D6 substrates such as metoprolol, sertraline, mirtazapine, and propranolol showed that CYP2D6 activity was higher in male subjects than in female subjects [14].

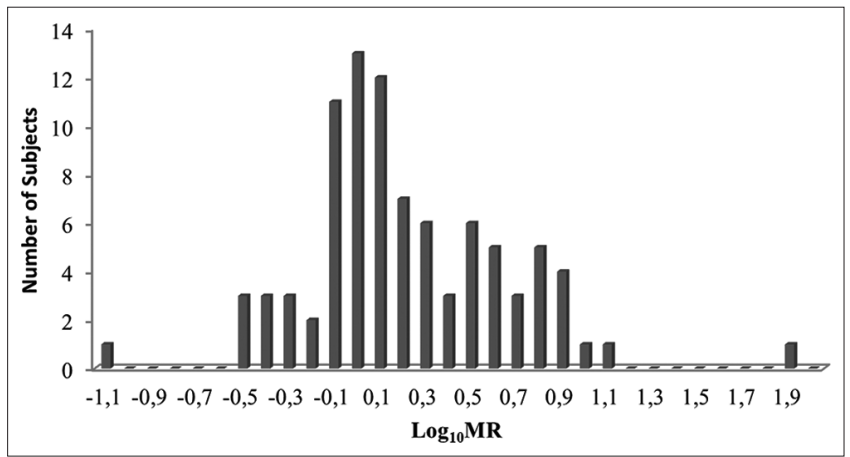

Fig. 1: Histogram of metoprolol/ $\alpha$-hydroxymetoprolol metabolic ratio from Javanese and Sundanese healthy subjects $(n=90)$

Table 2: CYP2D6 phenotype data

\begin{tabular}{|c|c|c|c|}
\hline Metabolic ratio metoprolol/ $\alpha$-hydroxymetoprolol & Phenotype & Number of subjects & Percentage $(\%)$ \\
\hline $\mathrm{MR}<0.1$ & Ultra rapid metabolizer & 1 & 1.11 \\
\hline $0.1<\mathrm{MR}<12.6$ & Extensive metabolizer & 88 & 97.78 \\
\hline $\mathrm{MR}>12.6$ & Poor metabolizer & 1 & 1.11 \\
\hline Total & & 90 & 100 \\
\hline
\end{tabular}

MR: Metabolic ratio 


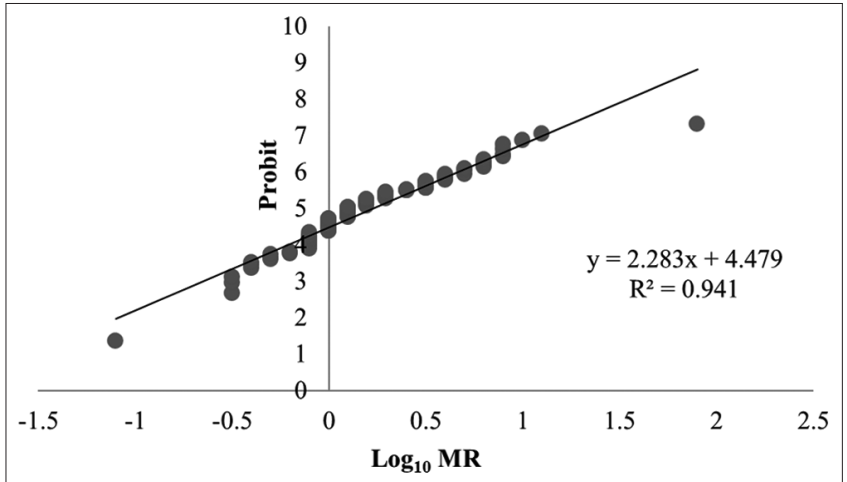

Fig. 2: Probit plot $\log _{10}$ metabolic ratio metoprolol $/ \alpha-$ hydroxymetoprolol

The frequencies of PM for the CYP2D6 phenotype (1.11\%) in this study are in concordance with most results of oxidation metabolizers in other Asian populations. The prevalence of PM in the Japanese population range from 0.3 to $0.5 \%$ in the Malaysian subjects amounted to $3.9 \%$ [15], in the Iran subject of at 2.5\%. CYP2D6 phenotyping study has been reported using metoprolol substrate or other substrates such as dextromethorphan, debrisoquine, and sparteine with consistent results that the presence of PM is low in Asian populations such as Japan, China, Korea, Malaysia, and Iran. Using debrisoquine as a substrate, PM on Malaysia's population is 3.9\% [15]. Using metoprolol as the substrate, the frequency of PM population in Korea, Japan, and China was $0.5 \%, 0.7 \%$, and $0 \%$, respectively [16]. The existence of PMs individual in Indonesian subjects $(1.11 \%)$ is lower than PMs in European and American countries (Caucasian individuals) such as the population of Britain (8.4\%) [17], Czech (8.7\%), and German (8.7\%) [18], Uruguay (7.3\%) [19], and Mexico (10\%) [20] and African countries such as Zimbabwe (5\%) [11] and Nigeria (3.5\%) [21].

The probit plot (Fig. 2) of the LogMR of all subjects shows a multimodal distribution profile. The plot also clarifies the existence of three phenotypes of the hydroxylation capacity of metoprolol. Fig. 1 shows that the mode value of the LogMR is -0.1 . The mode values in this Indonesian subjects are shifted to the right when compared to Japanese subjects (mode: -0.8 ) and shifted to the left when compared to Chinese subjects (mode: 0.7) [22]. This shows that the hydroxylation capacity of Indonesian subjects is stronger than Japanese subjects but is weaker than Chinese subjects.

This polymorphism of CYP2D6 among Javanese had similarity with the polymorphism of CYP2A6 among the same genetic ethnic of Javanese [23]. Genetically, CYP2A6* 4 was found higher compared to the occurrence of CYP2A6* 1 among smoking and non-smoking subject. The distribution of these allele frequencies was different among those two types of subjects.

The MR data in the CYP2D6 phenotyping study using dextromethorphan as the substrate in the Chinese population (120 people) showed a bimodal distribution and about $36 \%$ of subjects were classified as IM [24]. However, the MR value in this phenotyping study involving 90 subjects has not been able to distinguish the extensive and IM.

\section{CONCLUSION}

Indonesian healthy subjects have different capacities to metabolize metoprolol through CYP2D6. The frequency of PM of CYP2D6 phenotype (1.11\%) in the Javanese and Sundanese is in conformity and comparable to other Asian populations. This study has not been able to identify IM. It needs the additional study using more subjects. Further study was needed to determine the CYP2D6 genotype in Javanese and Sundanese populations. The results of this study might be helpful in patient dose adjusting to achieve the therapeutic goals.

\section{ACKNOWLEDGMENTS}

The authors thank the Directorate General of Higher Education Ministry of Research and Higher Education of the Republic of Indonesia and all the participants who have been involved in this study.

\section{CONFLICTS OF INTEREST}

All authors have none to declare.

\section{REFERENCES}

1. Ingelman-Sundberg M. Genetic polymorphisms of cytochrome P450 2D6 (CYP2D6): Clinical consequences, evolutionary aspects and functional diversity. Pharmacogenomics J 2005;5:6-13.

2. Shimada $T$, Yamazaki $H$, Mimura $M$, Inui $Y$, Guengerich FP. Interindividual variations in human liver cytochrome P-450 enzymes involved in the oxidation of drugs, carcinogens and toxic chemicals: Studies with liver microsomes of 30 Japanese and 30 caucasians. J Pharmacol Exp Ther 1994;270:414-23.

3. Zanger UM, Raimundo S, Eichelbaum M. Cytochrome P450 2D6: Overview and update on pharmacology, genetics, biochemistry. Naunyn Schmiedebergs Arch Pharmacol 2004;369:23-37.

4. Ozdemir M, Crewe KH, Tucker GT, Rostami-Hodjegan A. Assessment of in vivo CYP2D6 activity: Differential sensitivity of commonly used probes to urine pH. J Clin Pharmacol 2004;44:1398-404.

5. Vittalrao AM, Thanusubramanian H, Kumari KM, Shaik AB. Pharmacotherapy of heart failure. Asian J Pharm Clin Res 2018;11:7887.

6. Venkateswarlu P, Kumar BN, Seshaiah K, Prasad VV. Selective and sensitive method for the determination of metoprolol in human plasma using liquid chromatography coupled with tandem mass spectrometry. Acta Pharm 2010;60:177-84

7. Fang J, Semple HA, Song J. Determination of metoprolol, and its four metabolites in dog plasma. J Chromatogr B Analyt Technol Biomed Life Sci 2004;809:9-14.

8. Vattipally M, Mahesh AK, Kodati D, Yellu NR. Population pharmacokinetics and clinical response of metoprolol in South Indian hyperternsive patients. Asian J Pharm Clin Res 2014;7:140-3.

9. Li Q, Wang R. Simultaneous analysis of tramadol, metoprolol and their metabolites in human plasma and urine by high performance liquid chromatography. Chin Med J (Engl) 2006;119:2013-7.

10. Meyer UA, Zanger UM. Molecular mechanisms of genetic polymorphisms of drug metabolism. Annu Rev Pharmacol Toxicol 1997;37:269-96

11. Masimirembwa C, Hasler J, Bertilssons L, Johansson I, Ekberg O, Ingelman-Sundberg M. Phenotype and genotype analysis of debrisoquine hydroxylase (CYP2D6) in a black Zimbabwean population. Reduced enzyme activity and evaluation of metabolic correlation of CYP2D6 probe drugs. Eur J Clin Pharmacol 1996;51:117-22.

12. Basci NE, Bozkurt A, Isimer A, Kayaalp SO. Correlation between the metabolic ratios of debrisoquine and metoprolol in Turkish subjects. Pharmacol Toxicol 1994;75:62-4

13. Labbé L, Sirois C, Pilote S, Arseneault M, Robitaille NM, Turgeon J, et al. Effect of gender, sex hormones, time variables and physiological urinary $\mathrm{pH}$ on apparent CYP2D6 activity as assessed by metabolic ratios of marker substrates. Pharmacogenetics 2000;10:425-38.

14. Franconi F, Brunelleschi S, Steardo L, Cuomo V. Gender differences in drug responses. Pharmacol Res 2007;55:81-95.

15. Ismail R, Hussein A, Teh LK, Nizam Isa M. CYP2D6 phenotypes among malays in Malaysia. J Clin Pharm Ther 2000;25:379-83.

16. Sohn DR, Shin SG, Park CW, Kusaka M, Chiba K, Ishizaki T, et al. Metoprolol oxidation polymorphism in a Korean population: Comparison with native Japanese and Chinese populations. Br J Clin Pharmacol 1991;32:504-7.

17. McGourty JC, Silas JH, Lennard MS, Tucker GT, Woods HF. Metoprolol metabolism and debrisoquine oxidation polymorphism population and family studies. Br J Clin Pharmacol 1985;20:555-66

18. Hadasová E, Franke G, Zschiesche M, Cesková E, Zelenková O, Siegmund W. Debrisoquine 4-hydroxylation and sulphamethazine $\mathrm{N}$-acetylation in patients with schizophrenia and major depression. Br J Clin Pharmacol 1996;41:428-31.

19. Estevez F, Giusti M, Parrillo S, Oxandabarat J. Dextromethorphan O-demethylation polymorphism in the Uruguayan population. Eur $\mathrm{J}$ Clin Pharmacol 1997;52:417-8.

20. López M, Guerrero J, Jung-Cook H, Alonso ME. CYP2D6 genotype and phenotype determination in a Mexican Mestizo population. Eur J 
Clin Pharmacol 2005;61:749-54

21. Ebeshi BU, Bolaji OO, Masimirembwa CM. Cytochrome P450 2D6 (CYP2D6) genotype and phenotype determinationin the Nigerian populations. Asian J Pharm Health Sci 2011:1:47-54.

22. Horai Y, Nakano M, Ishizaki T, Ishikawa $\mathrm{K}$, Zhou HH, Zhou BI, et al. Metoprolol and mephenytoin oxidation polymorphisms in far Eastern oriental subjects: Japanese versus mainland Chinese. Clin Pharmacol
Ther 1989;46:198-207.

23. Patramurti C, Sugiyanto S, Nurrochmad A, Martono S. Polymorphism of cytochrome P450 2A6 (CYP2A6*1 and CYP2A6*4) among Javanese Indonesian smoker and non smoker. Ind J Pharm 2015;6:11-9.

24. Cai WM, Chen B, Liu YX, Chu X. Dextromethorphan metabolic phenotyping in a Chinese population. Zhongguo Yao Li Xue Bao 1997;18:441-4. 